\title{
Practice parameters for sublingual immunotherapy
}

C. Ortolani1, F. Agostinis², S. Amoroso3, R. Ariano4, A. Barbato5, M. Bassi6, G. Cadario7, P. Campi8, F. Cardinale9, G. Ciprandi10, R. D’Anneo11, M. Di Gioacchino12, V. Di Rienzo13, A. Fiocchi14, M. Galimberti15, E. Galli16, M. Giovannini17, C. Incorvaia18, S. La Grutta19, C. Lombardi20, F. Marcucci21, G. Marseglia22, M. Minelli23, A. Musarra24, E. Nettis25, E. Novembre26, G. Pajno27, G. Patriarca28, F. Pezzuto29, P. Piras30, S. Pucci31, A. Romano32, C. Romano33, O. Quercia34, G. Scala35, D. Schiavino28, G. Senna36, G. Sforza37, M. Tosca38, S. Tripodi39, F. Frati40

ABSTRACT: Practice parameters for sublingual immunotherapy. C. Ortolani, F. Agostinis, S. Amoroso, R. Ariano, A. Barbato, M. Bassi, G. Cadario, P. Campi, F. Cardinale, G. Ciprandi, R. D'Anneo, M. Di Gioacchino, V. Di Rienzo, A. Fiocchi, M. Galimberti, E. Galli, M. Giovannini, C. Incorvaia, S. La Grutta, C. Lombardi, F. Marcucci, G. Marseglia, M. Minelli, A. Musarra, E. Nettis, E. Novembre, G. Pajno, G. Patriarca, F. Pezzuto, P. Piras, S. Pucci, A. Romano, C. Romano, O. Quercia, G. Scala, D. Schiavino, G. Senna, G. Sforza, M. Tosca, S. Tripodi, F. Frati.

The efficacy and safety of sublingual immunotherapy (SLIT) are currently supported by clinical trials, metaanalysis and post-marketing surveys. Practice parameters for clinical use of SLIT are proposed here by a panel of Italian specialists, with reference to evidence based criteria.

Indications to SLIT include allergic rhinoconjunctivitis, asthma, and isolated conjunctivitis (strength of recommendation: grade A). As to severity of the disease, SLIT is indicated in moderate/severe intermittent rhinitis, persistent rhinitis and mild to moderate asthma (grade D).

SLIT may be safely prescribed also in children aged three to five years (grade B), and its use in subjects aged more than 60 years is not prevented when the indications and contraindication are ascertained (grade D).

The choice of the allergen to be employed for SLIT should be made in accordance with the combination of clinical history and results of skin prick tests (grade D). Polysensitisation, i.e. the occurrence of multiple positive response does not exclude SLIT, which may be done with the clinically most important allergens (grade D).

As to practical administration, co-seasonal, pre co-seasonal, and continuous schedules are available, being the latter recommended for perennial allergens or for pollens with particularly prolonged pollination, such as Parietaria (grade D). For pollens with relatively short pollination, such as grasses and trees (cypress, birch, alder, hazelnut, olive) the pre coseasonal and perennial schedules are preferred (grade C).

The build-up phases suggested by manufacturers can be safely used (grade A), but they can be modified according to the patient's tolerance (grade C). A duration of SLIT of 3-5 years is recommended to ensure a long-lasting clinical effect after the treatment has been terminated (grade $\mathrm{C}$ ). Monaldi Arch Chest Dis 2006; 65: 1, 44-46.

Keywords: Sublingual immunotherapy, rhinitis, asthma, conjunctivitis.

1 Casa di Cura Ambrosiana, Cesano Boscone, Milan 2 Allergy Consultant, Pediatrics Macedonio Melloni Hospital, Milan

3 Unità di Allergologia, Ospedale Civico, Palermo

4 ASL 1 Imperiese, Allergology Department, Bordighera, Imperia

5 University Department of Pediatrics, Padova

${ }^{6}$ Rho Hospital, Pediatrics, Rho

7 Le Molinette Hospital, Torino

8 Allergology Department, ASL n. 10 FI, S. Giovanni di Dio

Hospital, Firenze

9 III Clinica Pediatrica, Policlinico di Bari, Bari

10 U.O. di Otorinolaringoiatria, S. Martino Hospital, Genova

11 Pneumology Department, Regina Margherita Hospital, Messina

12 Dipartimento di Medicina e Scienza dell'Invecchiamento, Immunologia e medicina del lavoro, G. D'Annunzio University, Chieti

13 Allergology Department, Poliambulatorio ASL FR, Frosinone 14 Pediatric Department, Macedonio Melloni Hospital, Milan 15 Allergology Department, Novara Hospital, Novara

16 Pediatric Allergology, F.B.F. S. Pietro Hospital, Roma

17 Pneumology Department, Lugo Hospital, Ravenna

18 Allergology/Pulmonary rehabilitation. Istituti Clinici di Perfezionamento, Milano

19 III Divisione di Pediatria, Sezione di Allergologia e Pneumologia, P.O.G. Di Cristina ARNAS Civico, Palermo

20 Divisione di Medicina, S. Orsola F.B.F., Brescia

21 Sezione di Terapia e Immuno-Allergologia Pediatrica, Dipartimento di Scienze Ginecologiche, Ostetriche e Pediatriche, Policlinico Monteluce, Perugia
22 Pediatric Allergology, S. Matteo Policlinico, Pavia

23 Ambulatorio di Allergologia, U.O. Medicina Generale, Ospedale Campi Salentina, Lecce

24 Ambulatorio di Allergologia, ASL Reggio Calabria

25 Cattedra Allergologia e Immunologia Clinica, Policlinico di Bari

26 Ambulatorio di Allergologia e Broncopneumologia, Dipartimento di Pediatria, Ospedale A. Meyer, Firenze

27 Clinica Pediatrica, Policlinico di Messina

28 Allergology Department, Policlinico Gemelli, Università Cattolica, Roma

29 Reparto di Allergologia e Immunologia, Ospedale Curteri, Mercato S. Severino, Salerno

30 Reparto di Otorinolaringoiatra - U.O. di Allergologia, Santissima Trinità Hospital, Cagliari

31 U.O. di Allergologia, Ospedale Civile Civitanova Marche, ASL 8, Macerata

32 Allergology, Complesso Integrato Clinica Columbus, Roma

33 U.O.S. Pediatric Allergology, ASL NA n. 5, De Luca \& Rossano Hospital, Napoli

34 Allergology Department, Ospedale per gli Infermi, Faenza

35 Ambulatorio di Allergologia, Loreto Crispi Hospital, Napoli

36 Allergology Department, Ospedale Civile maggiore di Borgo Trento, Verona

37 Allergology Department, ASL BA/1, Andria, Bari

38 Pediatria Allergologica, Gaslini Hospital, Genova

39 Allergologia Pediatrica, Sandro Pertini Hospital, Roma

40 Scientific Department, Stallergénes, Milan, Italy. 


\section{Introduction}

Sublingual immunotherapy (SLIT) has received great interest since its introduction [1-3], and is currently considered a viable alternative to subcutaneous immunotherapy (SCIT). In recent years the scientific evidence on SLIT was further integrated by a meta-analysis study of efficacy [4], by reviews and large surveys on the safety [5-8], and other clinical aspects were investigated as well. As to efficacy, the meta-analysis in adults could yield the number of patients needed to ensure the strongest evidence [4] while the few studies addressed with children prevent as yet to reach similarly sound conclusions [9] though a clear benefit was reported in single studies $[10,11]$. In addition, clinical effectiveness was apparent concerning miteinduced asthma also from systematic review [9].

A panel of Italian specialists accomplished in allergen immunotherapy was formed to propose practice parameters of SLIT to be used to perform such treatment, considering all the literature and, when unavailable, their clinical experience. Regarding the latter, the statements were derived from the specialist's answers to a questionnaire dealing with the practical aspects of SLIT. These parameters are specifically addressed with practical use of SLIT, regarding the indications, the choice of allergens to employ, the schedules of administration, the duration and monitoring of treatment, and refer to the commonly used form of sublingual/swallow immunotherapy, in which the allergen extract is kept under the tongue for a few minutes and then swallowed, since the so called sublingual/spit form, in which the extract is spat out, has been insufficiently studied.

The scientific evidence was classified according to Shekelle et al. [12], who introduced four grades of recommendation of strength of based on six categories of evidence (table 1).

\section{Indications to SLIT}

According to placebo-controlled studies, SLIT has a grade $\mathrm{A}$ strength of recommendation for treating allergic rhinitis/rhinoconjunctivitis [4] and allergic asthma [13], and this completely agrees with the current concept of rhinitis and asthma as manifestations of a same allergic syndrome. Similar recommendation is also available for isolated allergic conjunctivitis [14].

Regarding the severity of the disease, rhinitis is currently classified in intermittent and persistent, both divided into mild and moderate/severe [3]. Intermittent allergic rhinitis is eligible for SLIT when moderate/severe, persistent allergic rhinitis also when mild, due to the duration of symptoms (grade D).

Asthma is similarly classified in intermittent, mild, moderate, and severe persistent [15]. Intermittent and mild to moderate persistent asthma is eligible for SLIT, while severe asthma must not be treated for safety reasons, unless drug treatment induces a step down of the disease to lower levels (grade D).

\section{Table 1. - Classification of scientific evidence}

\section{CATEGORY OF EVIDENCE}

Ia: evidence from meta-analysis of randomised controlled studies

Ib: evidence from at least one randomised controlled study

IIa: evidence from at least one controlled study without randomisation

IIb: evidence from at least one other type of quasi-experimental study

III: evidence from non-experimental descriptive studies, such as comparative studies, correlation studies, and case-control studies

IV: evidence from expert committee reports or opinions or clinical experience of respected authorities, or both

\section{STRENGTH OF RECOMMENDATION}

A: directly based on category I evidence

B: directly based on category II evidence or extrapolated recommendation from category I evidence

C: directly based on category III evidence or extrapolated recommendation from category I or II evidence

D: directly based on category IV evidence or extrapolated recommendation from category I, II or III evidence

Concerning the patient's age, recent data has shown that the occurrence rate and severity of adverse events in children aged 3-5 years [16-18] does not differ from other age ranges. Therefore, the age of 3 years or greater can be considered adequate to start the treatment (grade B). In adults, there is, in principle, no upper limit of age for starting SLIT, but over 60 years the allergic mechanism and the causal role of allergen (s), must be clearly documented and other causes of respiratory diseases must be ruled out (grade D).

When deciding to use SLIT instead of SCIT, some important factors must be considered: the fact that SCIT is relatively contraindicated in children younger than 5 years, the patient's preference, and the expected compliance, recently evaluated in SLIT treated subjects $[19,20]$ and in one study [20] compared to SCIT (grade C).

\section{Choice of the allergen (s)}

The choice of allergen to be employed for SLIT should be made, as for SCIT, according to the combination of clinical history and results of skin prick tests; a combination of clinical history and in vitro IgE tests are acceptable when skin prick tests cannot be performed (grade D).

The presence of polysensitization, i.e. of multiple positive response to diagnostic tests does not exclude SLIT: in such case the clinically most important allergen (s) must be used for treatment, and mixtures of several allergens must be avoided (grade D). If the use of only one allergen is decided, it is preferable to perform SLIT with the perennial instead of the seasonal allergen (grade D). 


\section{Schedules of administration}

Co-seasonal (which commences at the beginning of pollen season and is interrupted at the end of the season each year), pre-co-seasonal (which commences before the pollen season and is interrupted at the end of the season each year), and continuous (which can commence at any time and is continued without interruption) schedules are available. The continuous administration is recommended for perennial allergens such as house dust mites, animal epithelia, and moulds, but also for pollens with particularly prolonged pollination, such as Parietaria (grade D). For pollens with relatively short pollination, such as grasses and trees (cypress, birch, alder, hazelnut, olive) the pre-co-seasonal schedules have to be preferred (grade $\mathrm{C}$ ).

The build-up phases suggested by manufacturers can be safely used (grade A), but they can be modified according to patient's tolerance and following some general rules [21], which essentially regard local reactions in the mouth or at gastrointestinal level (grade C).

In case of momentary interruption of SLIT, it is advisable to restart the treatment from the buildup phase if more than 40 days have passed from the latest administration (grade D).

\section{Duration of treatment and monitoring}

According to follow-up studies [22] a duration of SLIT of 3-5 years can be recommended to ensure a long-lasting clinical effect after stopping the treatment (grade C). This can be applied to any allergen used for treatment (grade D).

To monitor the efficacy of the treatment, clinical data (severity and duration of allergic symptoms, drug consumption, and quality of life) is adequate. Among immunological parameters, the possible reduction of the skin prick test response to the specific allergen can be used as an indicator of decrease of sensitivity induced by SLIT, while in vitro measurement of specific $\operatorname{IgE}$ or IgG antibodies are of secondary importance (grade D).

\section{Dr. Frati is Scientific Director of Stallergenes Italia.}

Acknowledgement: The authors thank Prof. Gianni Passalacqua for his assistance and scientific contribute.

\section{References}

1. Malling HJ, Weeke B (eds). Immunotherapy. Position Paper of the European Academy of Allergology and Clinical Immunology. Allergy 1993; 48 (suppl 14): 9-35.

2. WHO Position Paper. Allergen immunotherapy: therapeutic vaccines for allergic diseases. Allergy 1998; 53 (Suppl 54): 4-30.

3. Bousquet J, van Cauwenberge P (eds). WHO initiative. Allergic rhinitis and its impact on asthma (ARIA). $J$ Allergy Clin Immunol 2001; 108 (suppl 5): 147-334.
4. Wilson DR, Torres-Lima M, Durham S. Sublingual immunotherapy for allergic rhinitis: systematic review and meta-analysis. Allergy 2005; 60: 4-12.

5. Gidaro G, Marcucci F, Sensi L, Incorvaia C, Frati F, Ciprandi G. The safety of sublingual-swallow immunotherapy: an analysis of published studies. Clin Exp Allergy 2005; 35: 565-71.

6. Di Rienzo V, Pagani A, Parmiani S, Passalacqua G, Canonica GW. Post-marketing surveillance study on the safety of sublingual immunotherapy in children. Allergy 1999; 54: 1110-1113.

7. Lombardi C, Gargioni S, Melchiorre A, et al. Safety of sublingual immunotherapy in adults: a post marketing surveillance study. Allergy 2001; 56: 889-92.

8. Pajno GB, Peroni DG, Vita D, Pietrobelli A, Parmiani S, Boner AL. Safety of Sublingual immunotherapy in children with asthma. Paediatr Drugs 2003; 5: 777-81.

9. Miceli-Sopo S, Macchiaiolo M, Zorzi G, Tripodi S. Sublingual immunotherapy in asthma and rhinoconjunctivitis: systematic review of paediatric literature. Arch Dis Child 2004; 89: 620-4.

10. Tari MG, Mancino M, Monti G. Efficacy of sublingual immunotherapy in patients with rhinitis and asthma due to house dust mite. A double-blind study. Allergol Immunopathol 1990; 18: 277-84.

11. La Rosa M, Ranno C, André C, et al. Double blind placebo controlled evaluation of sublingual swallow immunotherapy with standardized parietaria judaica extract in children with allergic rhinoconjunctivitis. $J \mathrm{Al}$ lergy Clin Immunol 1999; 104: 425-432.

12. Shekelle PG, Woolf SH, Eccles M, Grimshaw J. Developing guidelines. BMJ 1999; 318: 593-96.

13. Bousquet J, Scheinmann P, Guinnepain MT, et al. Sublingual-swallow immunotherapy (SLIT) in patients with asthma due to house-dust mites: a double-blind, placebo controlled study. Allergy 1999; 54: 249-60.

14. Mortemousque B, Bertel F, De Casamayor J, Verin P, Colin J. House-Dust Mite Sublingual-Swallow Immunotherapy in perennial conjunctivitis: a double-blind, placebocontrolled study. Clin Exp Allergy 2003; 33: 464-9.

15. Global Initiative for Asthma (GINA). Global strategy for asthma management and prevention. NHLBI/WHO workshop report, NIH publication no. 95-3659. Bethesda, US Department of Health and Human Services, updated 2002

16. Agostinis F, Tellarini L, Canonica GW, Falagiani P, Passalacqua G. Safety of sublingual immunotherapy with a monomeric allergoid in very young children. Allergy 2005; 60: 133.

17. Di Rienzo V, Minelli M, Musarra A, Sambugaro R, Pecora S, Canonica GW, Passalacqua G. Post-marketing survey on the safety of sublingual immunotherapy in children below the age of 5 years. Clin Exp Allergy 2005; 35: 560-4.

18. Fiocchi A, Pajno G, La Grutta S, et al. Safety of sublingual-swallow immunotherapy in children aged 3 to 7 years. Ann Allergy Asthma Immunol 2005; 95: 254-58.

19. Lombardi C, Gani F, Landi M, et al. Quantitative assessment of the adherence to sublingual immunotherapy. J Allergy Clin Immunol 2004; 113: 1219-20.

20. Pajno GB, Vita D, Caminiti L, et al. Children's compliance with allergen immunotherapy according to administration routes. J Allergy Clin Immunol 2005; 116: 1380-1.

21. Frati F, Sensi L, Di Rienzo V, Senna GE, Incorvaia C, Marcucci F. A model for management of sublingual immunotherapy. Allergol Immunol 2003; 35: 56-60.

22. Di Rienzo V, Marcucci F, Puccinelli P, et al. Long-lasting effect of sublingual immunotherapy in children with asthma due to house dust mite: a 10-year prospective study. Clin Exp Allergy 2003; 33: 206-10. 